\title{
- Enamel Wear of Teeth Against Polished and Glazed Monolithic Zirconia Crowns at 3 and 6 Months: A Clinical Study \\ IJCRR \\ Section: Healthcare
} ISI Impact Factor (2019-20): 1.628 IC Value (2019): 90.81 $\operatorname{SJIF}(2020)=7.893$

(c) (i) (3)

Copyright@IJCRR

\section{Prathap Ananth ${ }^{1}$, V. Vidyashree Nandini' ${ }^{2}$, M. Dilip Kumar ${ }^{3}$, KM Thamaraiselvan ${ }^{4}$}

\begin{abstract}
'Prosthodontist, Former Postgraduate, Department of Prosthodontics and Implantology, SRM Kattankulathur Dental College and Hospital, SRM Institute of Science \& Technology, Potheri-603203, Tamil Nadu, India; 'Professor and Head, Department of Prosthodontics and Implantology, SRM Kattankulathur Dental College and Hospital, SRM Institute of Science \& Technology, Potheri-603203, Tamil Nadu, India; ${ }^{3 R e a d e r, ~}$ Department of Prosthodontics and Implantology, SRM Kattankulathur DentalCollege and Hospital, SRM Institute of Science \& Technology, Potheri-603203, Tamil Nadu, India; 4 Senior Lecturer, Department of Prosthodontics and Implantology, SRM Kattankulathur Dental College and Hospital, SRM Institute of Science \& Technology, Potheri-603203, Tamil Nadu, India.
\end{abstract}

\section{ABSTRACT}

Background: The study compared and evaluated the wear of enamel opposing monolithic zirconia crowns finished with polished and glazed surfaces and also evaluated the surface wear of two different crown types at 3 and 6 months of clinical use.

Material and Methods: Eighteen participants (21-45 years) requiring single posterior restorations with healthy opposing natural dentition were selected. In all, 20 monolithic zirconia crowns $(n=20)$ were fabricated: 10- polished (PO), 10- polished and glazed (PG). For wear evaluation, participants were reviewed at 1 week, 3, 6 months following crown cementation. Casts from polyvinyl siloxane impressions were digitized using a blue light-emitting diode scanner and wear analysis was done using 3D superimposition software. The mean wear of enamel, their opposing crown groups were compared at 3 and 6 months using the unpaired T-test.

Results: The mean wear of enamel opposing PO and PG group at 3 and 6 months was $0.016 \pm 0.005 \mathrm{~mm}, 0.023 \pm 0.006 \mathrm{~mm}$ and $0.021 \pm 0.005,0.027 \pm 0.006 \mathrm{~mm}$ respectively (Statistically significant, $p<0.005$ ). The mean wear of the crown groups at 3 months was $0.013 \pm 0.004 \mathrm{~mm}(\mathrm{PO})$ and $0.014 \pm 0.004 \mathrm{~mm}(\mathrm{PG})$ (Statistically not significant, $p>0.005$ ). However, after 6 months, the values were $0.018 \pm 0.005 \mathrm{~mm}(P O)$ and $0.022 \pm 0.008 \mathrm{~mm}(P G)$ which was significant $(p<0.005)$.

Conclusions: Glazed crowns showed higher material loss and wear of opposing enamel at 6 months of clinical use. Monolithic Zirconia crowns should be preferably polished and not glazed to avoid opposing enamel wear.

Key Words: Crowns, Dentition, Monolithic, Superimposition, Tooth Wear, Zirconia

\section{INTRODUCTION}

Zirconia-based restorations have gained popularity over the years and are currently used in day-to-day dental practice. They are considered the strongest of tooth-coloured restorations because of their high flexural strength, hardness, and fracture toughness values. They present as an ideal material for the replacement of anterior and posterior teeth and also for implant prostheses.

The conventional zirconia restorations were usually layered with veneering porcelain to mask the opaque nature of the zirconia core. This often led to the fracture of the veneering ceramic as a result of weak interphase. Currently, fully contoured monolithic zirconia restorations are widely being used as they do not require a veneering ceramic and therefore offers a better advantage like minimal tooth reduction and fewer reported failures due to veneer chipping.

These restorations were harder than the natural teeth and had a compressive strength of $2000 \mathrm{Mpa}$, thereby increasing the potential for opposing enamel wear. Since, these restorations mandatorily required surface finishing after chairside occlusal adjustments to reduce the wear of opposing enamel, a polishing system or glazing process had to be routinely used to achieve the necessary surface finish.

The ideal surface finish for these restorations is still debatable as various in-vitro studies ${ }^{1-14}$ and a few in vivo studies ${ }^{15-18}$

\section{Corresponding Author:}

Dr. V. Vidyashree Nandini, MDS, DNB, Professor and Head, Department of Prosthodontics and Implantology, SRM Kattankulathur Dental College and Hospital, SRM IST, Kattankulathur Campus, Chennai, Tamil Nadu, India; E-mail: drvidyashreev@gmail.com

ISSN: 2231-2196 (Print)

Received: 26.01 .2021
ISSN: 0975-5241 (Online)

Revised: 14.03 .2021
Accepted: 04.05 .2021 
are there, comparing the effects of surface finish of monolithic zirconia on antagonistic enamel wear. Also, the result from in-vitro studies varied compared to an in-vivo setup due to the dynamic nature of the oral environment. It was important to assess the long-term effects of the commonly employed polishing and glazing process of monolithic zirconia on the opposing enamel surface wear. This clinical study was conducted with the research hypothesis that the surface finishing procedures employed like the polishing and glazing of monolithic zirconia caused different/dissimilar rates of wear of opposing enamel. The study aimed at assessing the wear of enamel opposing polished and glazed monolithic zirconia restorations and also the restorative wear at 3 and 6 months of clinical use.

\section{MATERIALS AND METHODS}

The present study was designed and ethical clearance was obtained from the institutional ethical committee (Ethics clearance no. 1248/IEC/2017) before the start of the study. A comparative interventional study design was adopted where the patients were allotted into two groups based on the type of crowns that they received (i.e polished (PO) or polished and glazed (PG) monolithic zirconia crowns). Participants were selected from the outpatient Department of Prosthodontics and Implantology, requiring crowns after endodontic management and included in the study after obtaining informed consent. 18 participants, between 21-45 years of age were chosen for the study. The selection of the participants was based on the inclusion and exclusion criteria.

\section{Participant Selection Criteria}

\section{Inclusion Criteria:}

Participants between 21-45 years of age, who belonged to ASA I and II and those who required single posterior monolithic zirconia crowns in the molar or premolar region, were selected. The opposing natural dentition should be free of wear facets and periodontally sound. Patients with minimal caries risk based on caries index and those with small occlusal restorations were also considered. A clinical crown height of at least $6-8 \mathrm{~mm}$ was required.

\section{Exclusion Criteria:}

Patients who belonged to ASA III and IV and those who showed signs of parafunctional habits, temporomandibular joint disorders and poor periodontal health were excluded from the study. Patients with missing antagonistic natural teeth and those with large occlusal restorations (Class II or IV) and untreated caries were also excluded from the selection process.

\section{Clinical and Laboratory Steps for crown fabri-}

\section{cation:}

For each patient, two sets of diagnostic impressions were made of the opposing arches using irreversible hydrocolloid (Zelgan plus, Dentsply India Pvt. Ltd, Gurgaon) and cast obtained in type III dental stone (Goldstone, Asian chemicals, Rajkot, India). The putty index was made (Aquasil, Dentsply, Konstanz, Germany) of the unprepared tooth (Buccolingual and Mesiodistal) on the diagnostic cast. This served as a reference for tooth preparation. Mock preparation was done on the diagnostic cast and a previously made putty index (mesiodistal and buccolingual) was used to standardize the preparation (Fig.1a,b).

Shade selection was done using a shade guide (VITAPAN Classic, VITA Zahnfabrik, Germany) before the tooth preparation procedure. The core build-up for the lost tooth structure was done with bulk-fill composite resin (Filtek Z350 $\mathrm{XT}, 3 \mathrm{M}$ ESPE, USA). Tooth preparation guidelines for monolithic zirconia crowns were followed (axial reduction of 1.5 $\mathrm{mm}$ and occlusal reduction of $2 \mathrm{~mm}) .{ }^{15} \mathrm{~A}$ convergence angle of 4 degrees was achieved with the help of the previously formed putty index. Equigingival, heavy chamfer finish line was given for the tooth preparations in all the subjects. The prepared tooth was thoroughly isolated, gingival retraction performed and a definitive impression of the prepared tooth was made with a custom tray using monophase polyvinyl siloxane impression material (Aquasil Monophase, Dentsply, Konstanz, Germany). The prepared tooth was restored with a provisional crown made from tooth-coloured chemically cured acrylic resin (DPI, India) by indirect technique.

The impression of the prepared tooth was poured using a type IV dental stone (UltrarockKalabhai Karson, Mumbai). A bite registration record was also made using Aluwax (Maarc bite registration wax, Dwaraka, Maharashtra, India). The models with the bite record were scanned and digitized using a CAD-CAM blue light LED scanner (D900 L, 3 Shape, Denmark). The working cast was analysed with the CAD-CAM software (3 Shape Dental System, Denmark) and the final restoration was designed and milled from pre-shaded monolithic zirconia blanks (NEXXZrT, Sagemax, USA) using a milling unit (Zenotec Hybrid Select, Wieland, Germany).

The restoration was subjected to a sintering process (Zenotec Fire cube, Wieland, Germany) at a temperature of $1520^{\circ} \mathrm{C}$ for 7 hours 20 minutes. A total of 20 crowns were milled and sintered.

\section{Surface Finishing and Crown Cementation:}

The crowns were checked for their fit and aesthetics intraorally. Occlusal adjustments were made after identifying interferences initially with a 100-micron articulating paper and later using a 12-micron articulation foil for the final elimination of the interferences (12-micron Arti-Fol metallic BK 28 and 100 microns- Bausch progress 100, Dental 
Co, USA) in maximum intercuspal position and excursive movements. Necessary adjustments were made with fine-grit sintered diamond point (TR -13 EF, Oro, Pune, India) under copious irrigation and light pressure. The adjusted crown surfaces were either just polished or polished and glazed before cementation.

All the 20 monolithic zirconia crowns were divided among 18 participants (two of the participants' required 2 crowns in the same arch) and categorized into two groups (Group PO and Group PG) randomly. Group PO comprised of 10 polished monolithic zirconia crowns and group PG comprised of 10 polished and glazed monolithic zirconia crowns. Each participant received a minimum of one and a maximum of two monolithic zirconia crowns with either of the two surface finishes. For group PO specimens, the polishing procedure was only employed following occlusal corrections. Zirconia polishing kit (Zilmaster, Shofu dental corporation, USA) which comprised of coarse (green band), medium (blue band) and fine (yellow band) diamond impregnated silicone points were used sequentially on a slow speed contrangled micromotor handpiece at $15000 \mathrm{rpm}$ and with minimal pressure application in a unidirectional motion to achieve the necessary surface polish.

For the group PG specimens, similar occlusal adjustments and polishing steps were performed followed by glazing of the restoration. Glaze in the form of powder and liquid (Ceramco3, Dentsply, Canada) was used for the process. Glazing was done by applying a thin even coat of glaze mixture over the crown surface with a glaze brush (Skyists No.0 brush, Japan). The crowns were subjected to $850^{\circ} \mathrm{C}$ for 10 minutes in a porcelain firing furnace (Programat P300, Ivoclar Vivadent, Germany). After the necessary surface finish was achieved, the crowns were cemented using Type I Glass Ionomer cement (Gold label, GC Products, Japan) following a proper isolation technique.

\section{Follow Up and Wear Evaluation:}

To check for opposing tooth enamel wear and also the crown material wear, a 3D superimposition technique was employed.15-18 Impressions were made of upper and lower arches at baseline i.e., 1 week, 3 months and 6 months after cementation using custom trays and monophase impression material (Aquasil Monophase, Dentsply, Konstanz, Germany). Type IV dental stone (Ultrarock, Kalabhai Karson, Mumbai, India) casts were prepared. The casts were obtained at 1 week, 3 months and 6 months post cementation for 3D scanning and wear analysis (Fig. 2).

The occlusal contact points of the zirconia crowns and their antagonists were intra-orally marked using articulating paper (100 $\mu \mathrm{m}$, Bausch progress 100, Bausch Dental Co, USA). The clinical status, particularly the marked occlusal contact points were photographed using a DSLR camera (EOS 600D
19 MP, Canon, Japan) to determine the occlusal contact areas (OCA) for wear measurement and the reference areas for occlusal matching (Fig.3 a,b). The cast obtained at baseline, 3 months and 6 months were scanned and digitized using a 3D blue light led scanner (D900, 3shape, Denmark) which had a scanning accuracy of $15 \mu \mathrm{m}$. The scanned data were analysed using three-dimensional analysis software (Geomagic Control X, 3D Systems, USA). The follow-up scan data of the upper and lower arches at 3 and 6 months were superimposed with the baseline data (1week) using the global auto aligning option to check for surface changes or wear on the antagonistic enamel and zirconia restoration.

A maximum of 25-micron deviation between two scanned images was allowed. Three wear points were selected on the functional cusps of the tooth of interest i.e. (tooth with the crowns and the antagonistic tooth) on the superimposed images at 3 months and 6 months after correlating it with the previously photographed occlusal contact points. The wear values were depicted as negative coordinates in millimetres on the selected contact points. (Fig.4a, b)(Fig.5a,b)

The extent of surface change of the 3 months and 6 months data from the baseline data was also represented as a colour deviation map. The green regions on the colour map represented superimposed areas within $25 \mu \mathrm{m}$ of positive or negative deviation. The regions marked as yellow, orange or red represented regions more than $25 \mu \mathrm{m}$ and regions marked in blue represented areas below $25 \mu \mathrm{m}$ of deviation (Fig.4a,b) (Fig.5a,b). The regions in the yellow, orange, red and blue regions were not considered for the evaluation of wear.

\section{Statistical Analysis:}

The data thus obtained were subjected to statistical analysis using the SPSS (IBM SPSS Statistics for Windows, Version 19.0: IBM Corp, Armonk, USA). Significance level was fixed at $5 \%(\alpha=0.05)$. Normality tests (KolmogorovSmirnov and Shapiro-Wilks tests) revealed that variables do not follow a normal distribution. Therefore, non-parametric tests namely, unpaired t-test and paired t-test was used to compare the data.

\section{RESULTS}

The mean wear of the polished and glazed enamel antagonists and crown groups were compared at 3 and 6 months statistically using the unpaired- t-test. The mean $\pm \mathrm{SD}$ wear values at 3 months for the natural tooth opposing polished crowns was $0.016 \pm 0.005 \mathrm{~mm}$ and for those opposing glazed crowns was $0.023 \pm 0.006 \mathrm{~mm}$ which was statistically significant $(p<0.005)$ (Fig 6) (Table.1). Similarly, the mean wear value at 6 months was $0.021 \pm 0.005 \mathrm{~mm}$ and $0.027 \pm 0.006$ $\mathrm{mm}$ which was also significant $(\mathrm{p}<0.005)$ (Fig.6) (Table.2). In the polished and glazed monolithic zirconia crown groups, 
the wear values were $0.013 \pm 0.004 \mathrm{~mm}$ and $0.014 \pm 0.004$ $\mathrm{mm}$ at 3 months which was not statistically significant $(\mathrm{p}>$ 0.005) (Fig 7) (Table 3). After 6 months, wear values for the polished crown-group were found to be $0.018 \pm 0.005 \mathrm{~mm}$ and for the glazed crown-group, it was $0.022 \pm 0.008 \mathrm{~mm}$ which was significant statistically $(\mathrm{p}<0.005)$ (Fig 7) (Table 4). The mean wear of the crowns groups and opposing enamel groups were compared between two time periods (i.e. 3 and 6 months) using the paired t-test. The mean enamel wear of teeth opposing polished zirconia crown was $0.016 \pm 0.05$ $\mathrm{mm}$ (3 months) and $0.021 \pm 0.005 \mathrm{~mm}$ (6 months) (Fig 8)(Table 5) and for the mean enamel wear of natural teeth opposing glazed crown-group was $0.023 \pm 0.006 \mathrm{~mm}$ and $0.027 \pm$ $0.006 \mathrm{~mm}$ (Fig 8)(Table 6) The mean material wear of the crown surface was found to be $0.013 \pm 0.004 \mathrm{~mm}$ ( 3 months) and $0.018 \pm 0.005 \mathrm{~mm}$ ( 6 months) for the polished group (Fig 9)(Table7) and 0.014 $\pm 0.04 \mathrm{~mm}$ (3 months) and 0.022 \pm $0.08 \mathrm{~mm}$ (6 months) of the glazed crown group (Fig 9)(Table. 8 ) which was also statistically significant as p-value was $0.0001(\mathrm{p}<0.005)$.

\section{DISCUSSION}

Many in vitro studies ${ }^{1-14}$ and few in vivo studies ${ }^{15-18}$ have reported on the effects of surface finish like polishing or glazing of monolithic zirconia on its wear potential on opposing natural enamel. Sabrah et al. ${ }^{5}$, in their study, found that polished zirconia was found to cause the least wear on synthetic hydroxyapatite in a two-body rotating pin-on-disk wear test as compared to glazed and machined zirconia (1.3, 2.7 and $2.7 \mathrm{~mm}^{3}$ ). Janyavula et al. ${ }^{1}$, evaluated the in vitro material loss and surface roughness properties of polished, glazed and polished and reglazed zirconia against enamel and compared the results with those of veneered ceramic and enamel. The results showed that glazed zirconia showed higher roughness values compared to its polished counterpart along with a higher coefficient of friction. Zirconia restorations needed to be polished before glazing to reduce wear. Kontos et al. ${ }^{4}$, in their in-vitro study, examined the surface treatment results on the wear of zirconia and antagonistic teeth using a pin on the disk apparatus. The authors' concluded that polished zirconia displayed minimal wear rates on the antagonists compared to other surface treatments. Beuer et al. ${ }^{2}$, in their in vitro study reported higher incidence wear of polished zirconia compared to its glazed and layered counterparts when opposed by stainless steel bearings. Al Hamad. KQ et al. ${ }^{19}$, in their in vitro study compared the surface roughness of three-layered zirconia and two monolithic zirconia groups based on various surface treatments like glazed, without glaze, finished, polished, super polished and super polished with diamond paste and found that there was no significant difference seen in the roughness values of monolithic zirconia groups that were super polished and super polished with diamond paste from the glazed group. Manzuic MM et al. ${ }^{20}$, in their study on the effect of glazing on the translucency, colour and surface roughness concluded that glazing of the specimens reduced the roughness values in all the specimens. The results of tooth wear from in-vitro studies varied and could not be quantified clinically.

Stober et al. ${ }^{15}$, in their in-vivo study, found that monolithic zirconia caused higher wear of opposing enamel when compared to their natural enamel counterparts. The authors' suggested the need for performing accurate finishing and polishing of the crown surface to reduce the wear rates.

In the present study the mean antagonistic enamel wear of teeth opposing polished zirconia after 6 months was $21 \mu \mathrm{m}$ and for the teeth opposing glazed zirconia was $27 \mu \mathrm{m}$ which showed that there was lesser enamel wear when opposed by polished crowns. The mean enamel wear values of teeth opposing the polished and glazed crowns in this study was lesser when compared with the study by Stober et al. ${ }^{15}$, which showed 6 months mean antagonist enamel wear value of 33 $\mu \mathrm{m}$ when they were opposed by polished monolithic zirconia crowns. Also, the mean surface wear values of the polished and glazed zirconia crowns at 6 months in this study was 18 $\mu \mathrm{m}$ and $22 \mu \mathrm{m}$ that was lesser when compared to the mean maximum wear values obtained for polished monolithic zirconia surface from an in vivo study on enamel wear opposing polished monolithic zirconia crowns by Esquivel-Upshaw et al. ${ }^{16},(38.4 \mu \mathrm{m}$ at 6 months $)$.

The mean enamel wear values were also higher for those opposing the glazed group than the polished group at 3 and 6 months and the result was clinically significant. There was no significant loss of material at the polished and glazed crown surfaces at 3 months, however, wear was found to increase and it became significant in the crown groups after 6 months. The glazed crowns and their opposing enamel group showed higher material loss which may have occurred due to the loss of the glaze layer from the crown surface following clinical use. ${ }^{13,21}$ The glaze particles in the glaze layer might have caused three-body surface wear between the crown and the opposing natural teeth. Also, heat treatment like glazing was found to alter the surface properties of the zirconia material like a reduction in the flexural strength and thereby increasing the surface roughness of the restoration. ${ }^{14,21}$ Mechanical processes like tooth brushing with fluoride and whitening dentifrices were also found to influence the surface roughness of polished and glazed monolithic zirconia. ${ }^{22}$ An increase in roughness was correlated with an increase in the contact area with moisture which could result in low-temperature degradation (LTD) of the material. LTD occurs through the slow and continuous phase transformation in the presence of water or humidity at temperatures of $100^{\circ} \mathrm{C}$. This process could lead to the degradation of zirconia material resulting in the exposure of stabilizers on its surface 
and thereby inducing wear on the opposing enamel through a three-body wear process. ${ }^{5}$ A thick glazing layer was found to result in errors in the intensity of contact of the restoration which may also increase wear rates. ${ }^{22}$

In this study participants chosen were all between the age group of 21 to 45 years and had a healthy opposing natural dentition. All impressions were made with customized impression trays using monophase impression material that helped in maintaining an even thickness of $2-3 \mathrm{~mm}$ of impression material in all regions compared to impressions made with stock trays that can have varying thicknesses causing distortion. ${ }^{23-25}$ Also, the latest $3 \mathrm{D}$ superimposition technique was used in this study that was similar to other in vivo studies ${ }^{15-17,26}$ and helped in quantifying enamel and crown wear. The limitations of the study included a relatively smaller sample size (of 20) and a short observation time of 3 to 6 months. The scanning accuracy of the scanner used in this study was about 15 microns. The detail reproduction with vinyl polysiloxane impression materials and type IV dental stone were in the range of 10 microns. Further clinical evaluation is necessary over a longer time duration as the technology is new. The factors like the effect of LTD, the varying bite force in different participants, the abrasiveness of the diet and habits can be included in the selection criteria in further studies. ${ }^{17,21}$. The bite force and occlusal contact points can be further standardized using occlusal assessment tools like the T scan.

\section{CONCLUSION}

Monolithic zirconia restoration even though being an ideal alternative for the conventional restorations, their potential to induce wear on the opposing enamel cannot be overlooked. The surface finishing technique that is employed has a vital role to play in reducing the wear. With the advancements in material research and the introduction of newer polishing systems for these restorations, there is an ever-growing need to assess the wear occurring at restoration-tooth interphase clinically. Within the limitations of this in-vivo study, it could be concluded that Monolithic Zirconia crowns should be preferably polished and not glazed to avoid wear of the opposing enamel. Polishing also resulted in lesser restoration wear. Glazing of monolithic zirconia was found to elicit higher surface wear of the crowns as well as of the opposing enamel at 3 and 6 months compared to the polished group.

Conflict of Interest: All authors have no conflict of interest to declare.

\section{ACKNOWLEDGEMENT}

We acknowledge the immense help received from the scholars whose articles are cited and included in references of this manuscript. We are also grateful to authors, editors and publishers of all those articles, journals and books from where the literature for this article has been reviewed and discussed.

Funding Information: No funding to declare.

\section{Authors' Contribution:}

1. Dr. Ananth Prathap (MDS- Prosthodontics Crown and Bridge)-Conception of the study, data collection, data analysis and interpretation, drafting the article, critical revision of the article

2. Dr. Vidyashree Nandini V (MDS- Prosthodontics Crown and Bridge), DNB*- Conception of the study, data analysis and interpretation, drafting the article, critical revision of the article, final approval of the article for publication

3. Dr. Dilip Kumar M (MDS- Prosthodontics Crown and Bridge)- Data Collection, critical review of the study

4. Dr. Thamarai Selvan KM (MDS- Prosthodontics Crown and Bridge)- Data Collection, data analysis and interpretation, critical review of the study

\section{REFERENCES}

1. Janyavula S, Lawson N, Cakir D, Beck P, Ramp LC, Burgess JO, et al. The wear of polished and glazed zirconia against enamel [published erratum appears in J Prosthet Dent 2015;114(1):159]. J Prosthet Dent. 2013;109(1):22-9.

2. Beuer F, Stimmelmayr M, Gueth JF, Edelhoff D, Naumann M. In vitro performance of full-contour zirconia single crowns. Dent Mater. 2012;28(4):449-56.

3. Kim MJ, Oh SH, Kim JH, Ju SW, Seo DG, Jun SH, Ahn JS, Ryu JJ, et al. Wear evaluation of the human enamel opposing different Y-TZP dental ceramics and other porcelains. J Dent. 2012;40(11): 979-88.

4. Kontos L, Schille C, Schweizer E, Geis-Gerstorfer J. Influence of surface treatment on the wear of solid zirconia. Acta Odontol. 2013;71:482-87.

5. Sabrah AH, Cook NB, Luangruangrong P, Hara AT, Bottino MC. Full-contour Y-TZP ceramic surface roughness effect on synthetic hydroxyapatite wear. Dent Mater. 2013;29(6):666-73.

6. Stawarczyk B, Özcan M, Schmutz F, Trottmann A, Roos M, Hämmerle $\mathrm{CH}$, et al. Two-body wear of monolithic, veneered and glazed zirconia and their corresponding enamel antagonists. Acta Odontol Scand. 2013;71(1):102-12.

7. Jung YS, Lee JW, Choi YJ, Ahn JS, Shin SW, Huh JB, et al. A study on the in-vitro wear of the natural tooth structure by opposing zirconia or dental porcelain. J Adv Prosthodont. 2010;2(3):111-5.

8. Sripetchdanond J, Leevailoj C. Wear of human enamel opposing monolithic zirconia, glass-ceramic, and composite resin: an in vitro study. J Prosthet Dent. 2014;112(5):1141-50.

9. Amer R, Kürklü D, Kateeb E, Seghi RR. Three-body wear potential of dental yttrium-stabilized zirconia ceramic after grinding, polishing, and glazing treatments. J Prosthet Dent. 2014;112(5):1151-5.

10. Preis V, Weiser F, Handel G, Rosentritt M. Wear performance of monolithic dental ceramics with different surface treatments. Quintessence Int. 2013;44(5):393-405. 
11. Mörmann WH, Stawarczyk B, Ender A, Sener B, Attin T, Mehl A, et al. Wear characteristics of current aesthetic dental restorative CAD/CAM materials: two-body wear, gloss retention, roughness and Martens hardness. J Mech Behav Biomed Mater. 2013;20:113-25.

12. Luangruangrong P, Cook NB, Sabrah AH, Hara AT, Bottino MC. Influence of full-contour zirconia surface roughness on wear of glass-ceramics. J Prosthodont. 2014;23(3):198-205.

13. Rupawala A, Musani SI, Madanshetty P, Dugal R, Shah UD, Sheth EJ, et al. A study on the wear of enamel caused by monolithic zirconia and the subsequent phase transformation compared to two other ceramic systems. J Indian Prosthodont Soc. 2017;17(1):8-14.

14. Gaonkar SH, Aras MA, Chitre V. An in vitro study to compare the surface roughness of glazed and chairside polished dental monolithic zirconia using two polishing systems. J Indian Prosthodont Soc. 2020;20(2):186-92.

15. Stober T, Bermejo JL, Rammelsberg P, Schmitter M. Enamel wear caused by monolithic zirconia crowns after 6 months of clinical use. J Oral Rehabil. 2014;41(4):314-22.

16. Esquivel-Upshaw JF, Kim MJ, Hsu SM, Abdulhameed N, Jenkins R, Neal D, Ren F, Clark AE, et al. Randomized clinical study of the wear of enamel antagonists against polished monolithic zirconia crowns. J Dent. 2018; 68:19-27.

17. Mundhe K, Jain V, Pruthi G, Shah N. Clinical study to evaluate the wear of natural enamel antagonist to zirconia and metalceramic crowns. J Prosthet Dent. 2015;114(3):358-63.

18. Lohbauer U, Reich S. Antagonist wear of monolithic zirconia crowns after 2 years. Clin Oral Investig. 2017;21(4):1165-72.

Table 1: Mean wear of Enamel Opposing Polished and Glazed Monolithic Zirconia Crowns at 3 months

\begin{tabular}{lcccc} 
Groups & 3 months wear & $\begin{array}{c}\text { Unpaired } \\
\text { T-test }\end{array}$ & P-value \\
& Mean & SEM & & \\
$\begin{array}{l}\text { Polished Zirconia } \\
\text { Antagonist wear }\end{array}$ & 0.016 & 0.001 & & \\
$\begin{array}{l}\text { Glazed Zirconia } \\
\text { Antagonist wear }\end{array}$ & 0.023 & 0.001 & -4.931 & 0.00o1 $^{*}$ \\
\hline
\end{tabular}

Table 2: Mean wear of Enamel Opposing Polished and Glazed Monolithic Zirconia Crownsat Crowns 6 months

\begin{tabular}{llcll} 
Groups & \multicolumn{2}{c}{6 months wear } & $\begin{array}{c}\text { Unpaired } \\
\text { T-test }\end{array}$ & P-value \\
& Mean & SEM & & \\
$\begin{array}{l}\text { Polished Zirconia } \\
\text { Antagonist wear }\end{array}$ & 0.021 & 0.001 & & \\
$\begin{array}{l}\text { Glazed Zirconia } \\
\text { Antagonist wear }\end{array}$ & 0.027 & 0.001 & -4.754 & o.ooo1 $^{*}$ \\
\hline
\end{tabular}

19. Al Hamad KQ, Abu Al-Addous AM, Al-Wahadni AM, Baba NZ, Goodacre BJ. Surface Roughness of Monolithic and Layered Zirconia Restorations at Different Stages of Finishing and Polishing: An In Vitro Study. J Prosthodont. 2019;28(7):818-25.

20. Manziuc MM, Gasparik C, Burde AV, Colosi HA, Negucioiu $\mathrm{M}$, Dudea D, et al. Effect of glazing on translucency, colour, and surface roughness of monolithic zirconia materials. J EsthetRestor Dent. 2019;31(5):478-85.

21. Oh WS, Delong R, Anusavice KJ. Factors affecting enamel and ceramic wear: a literature review. J Prosthet Dent. 2002;87(4):451-9.

22. Lee JH, Kim SH, Han JS, Yeo IL, Yoon HI. Optical and Surface Properties of Monolithic Zirconia after Simulated Toothbrushing. Materials 2019;12(7):1158.

23. Schnell RJ, Phillips RW. Dimensional stability of rubber base impressions and certain other factors affecting accuracy. J Am Dent Assoc. 1958;57(1):39-48.

24. Gilmore WH, Schnell RJ, Phillips RW. Factors influencing the accuracy of silicone impression materials. J Prosthet Dent. 1959;9(2):304-14.

25. Eames WB, Sieweke JC, Wallace SW, Rogers LB. Elastomeric impression materials: Effect of bulk on accuracy. J Prosthet Dent. 1979; (41):304-7.

26. Etman MK, Woolford M, Dunne S. Quantitative measurement of the tooth and ceramic wear: in vivo study[published erratum appears in Int J Prosthodont 2008;21(6):508]. Int J Prosthodont. 2008;21(3):245-52.

Table 3: Mean Wear of Polished and Glazed Monolithic Zirconia Crowns at 3 months

\begin{tabular}{lcccc} 
Groups & 3 months wear & $\begin{array}{c}\text { Unpaired } \\
\text { T-test }\end{array}$ & P-value \\
& Mean & SEM & & \\
$\begin{array}{l}\text { Polished Zirconia } \\
\text { Crown wear }\end{array}$ & 0.013 & 0.001 & & \\
$\begin{array}{l}\text { Glazed Zirconia } \\
\text { Crown wear }\end{array}$ & 0.014 & 0.001 & -0.698 & 0.488 \\
\hline
\end{tabular}

Table 4: Mean Wear of Polished and Glazed Monolithic Zirconia Crowns at 6 months

\begin{tabular}{lcccc} 
Groups & 6 months wear & $\begin{array}{c}\text { Unpaired } \\
\text { T-test }\end{array}$ & P-value \\
& Mean & SEM & & \\
$\begin{array}{l}\text { Polished Zirconia } \\
\text { Crown wear }\end{array}$ & 0.018 & 0.001 & & \\
$\begin{array}{l}\text { Glazed Zirconia } \\
\text { Crown wear }\end{array}$ & 0.022 & 0.002 & -2.661 & 0.010 \\
\hline
\end{tabular}


Table 5: Difference in the mean wear of antagonistic natural teeth (enamel) opposing polished monolithic zirconia crowns at 3 months and 6 months' time interval

\begin{tabular}{llll} 
Groups & $\begin{array}{l}\text { Polished Zirconia } \\
\text { Antagonist wear }\end{array}$ & $\begin{array}{l}\text { Paired } \\
\text { T-test }\end{array}$ & $\begin{array}{l}\text { P- } \\
\text { value }\end{array}$ \\
& Mean & SEM \\
0.0001*- & \\
5.9090.0010.0163 & & \\
months & & \\
o.0010.0216 months & & \\
\hline
\end{tabular}

Table 6: Difference in the mean wear of antagonistic natural teeth (enamel) opposing glazed monolithic zirconia crowns at 3 months and 6 months' time interval

\begin{tabular}{lllcl} 
Groups & \multicolumn{2}{l}{ Glazed Zirconia } & Paired T-test & P-value \\
& Antagonist wear & & \\
& Mean & SEM & & \\
3 months & 0.023 & 0.001 & -5.017 & 0.00o1 $^{*}$ \\
6 months & 0.027 & 0.001 & & \\
\hline
\end{tabular}

Table 7: Difference in the mean wear of polished monolithic zirconia crowns at 3 months and 6 months' time interval

\begin{tabular}{|c|c|c|c|c|}
\hline \multirow[t]{2}{*}{ Groups } & \multicolumn{2}{|c|}{$\begin{array}{l}\text { Polished Zirconia } \\
\text { Crown wear }\end{array}$} & \multirow[t]{2}{*}{ Paired T-test } & \multirow[t]{2}{*}{ P-value } \\
\hline & Mean & SEM & & \\
\hline 3 months & 0.013 & 0.001 & \multirow{2}{*}{-5.603} & \multirow{2}{*}{$0.0001^{*}$} \\
\hline 6 months & 0.018 & 0.001 & & \\
\hline
\end{tabular}

Table 8: Difference in the mean wear of glazed monolithic zirconia crowns at 3 months and 6 months' time interval

\begin{tabular}{lcccc} 
Groups & \multicolumn{2}{c}{$\begin{array}{c}\text { Glazed Zirconia } \\
\text { Crown wear }\end{array}$} & Paired T-test & P-value \\
& Mean & SEM & & \\
3 months & 0.014 & 0.001 & -8.580 & $0^{0.0001^{*}}$ \\
6 months & 0.022 & 0.002 & & \\
\hline
\end{tabular}

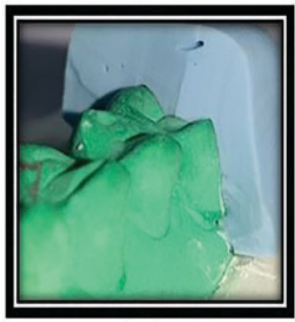

(a)

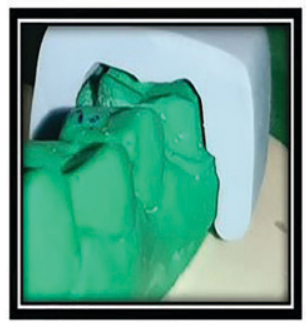

(b)
Figure 1: (a) Putty Index made before preparation, (b) Putty impression used for verifying the mock preparation.

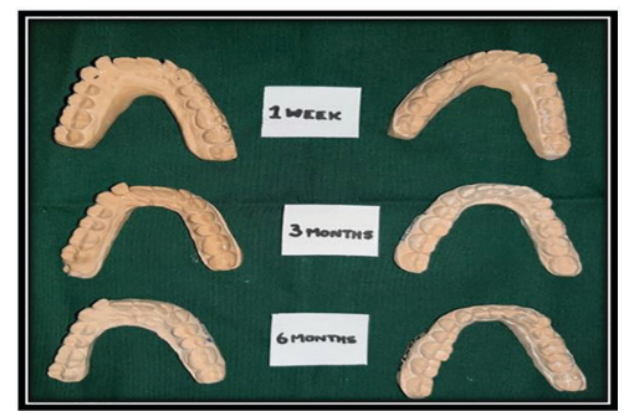

Figure 2: Cast Obtained at 1 Week, 3 Months' and 6 Months for 3D Scanning and Wear Analysis.

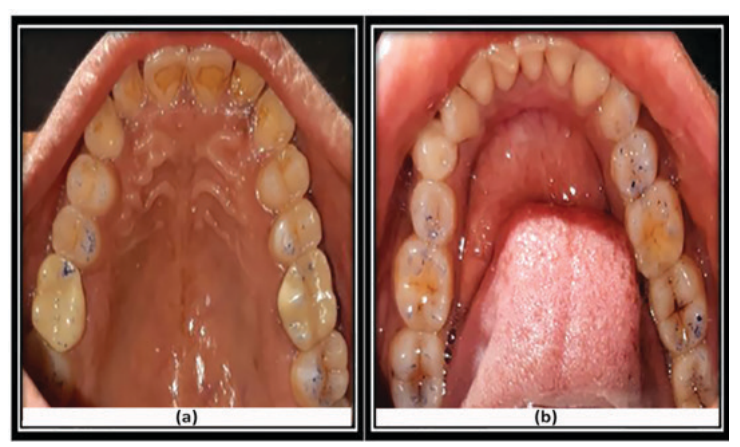

Figure 3: Occlusal Contact Points Photographed on the (a) Crowns and (b) Antagonistic Tooth.

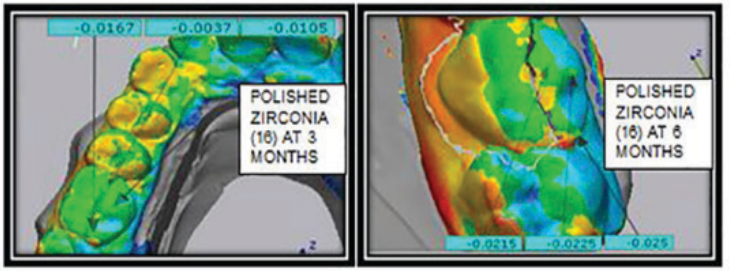

(a)

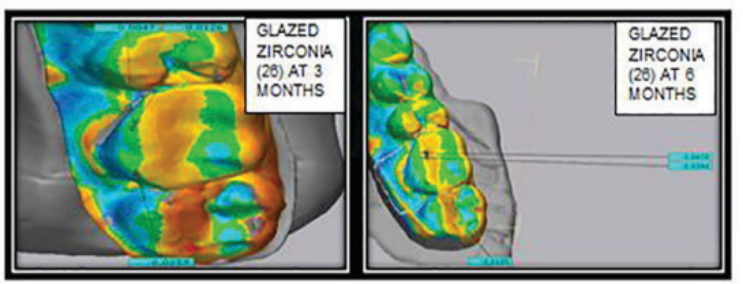

(b)

Figure 4: Three wear points were selected on the functional cusp of (a) Polished and (b) Glazed zirconia crown at 3 and 6 months. 


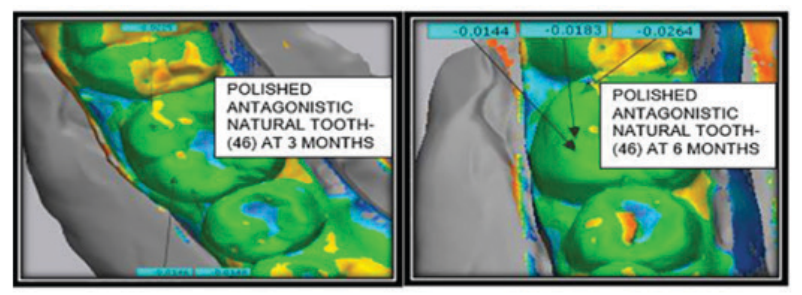

(a)

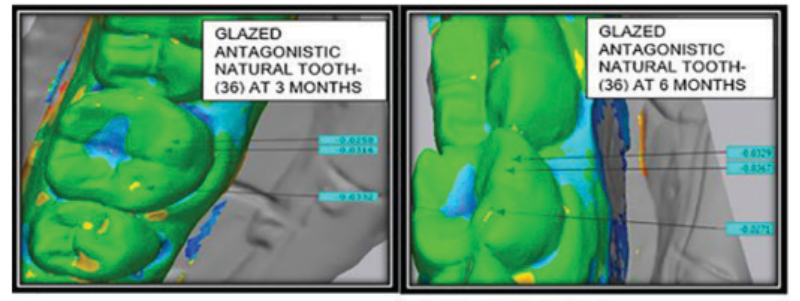

(b)

Figure 5: Three wear points selected on the functional cusp of antagonistic natural tooth opposing (a) Polished zirconia crown and (b) Glazed zirconia crown at 3 and 6 months.

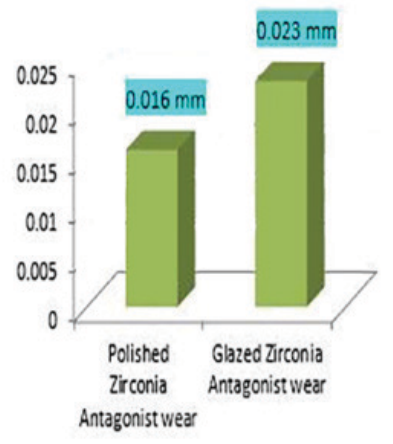

AT 3 MONTHS

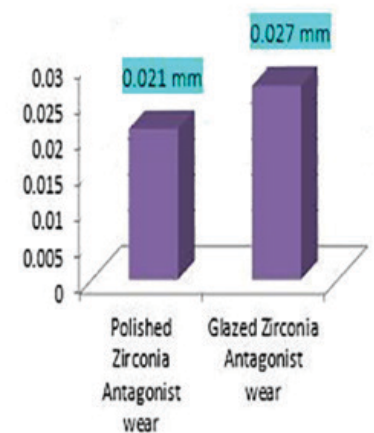

AT 6 MONTHS
Figure 6: Comparison of mean wear of antagonistic natural teeth (enamel) opposing polished and glazed monolithic zirconia crowns at 3 months' and 6 months'.

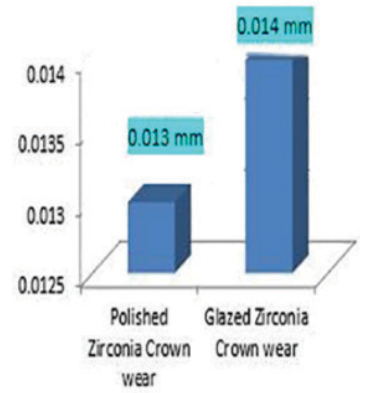

AT 3MONTHS

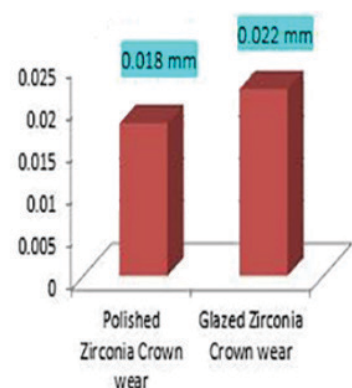

AT 6 MONTHS
Figure 7: Comparison of mean wear of polished and glazed monolithic zirconia crowns at 3 months' and 6 months'.

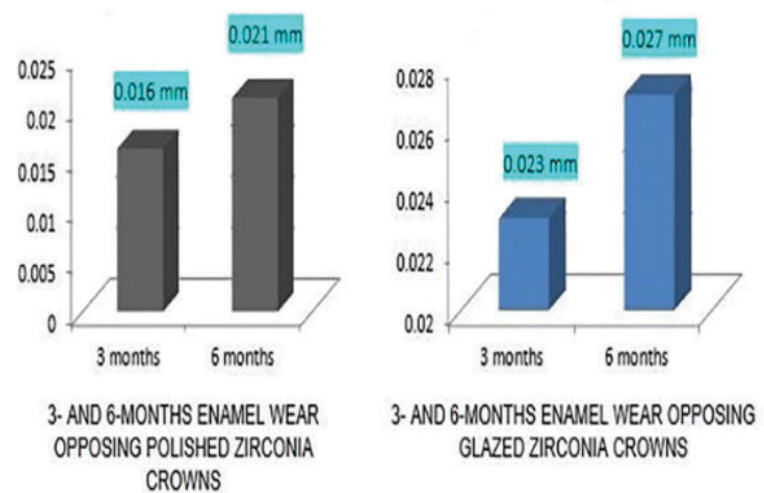

Figure 8: The difference in the mean wear of antagonistic natural teeth (enamel) opposing polished and glazed monolithic zirconia crowns at 3 months' and 6months' time interval.

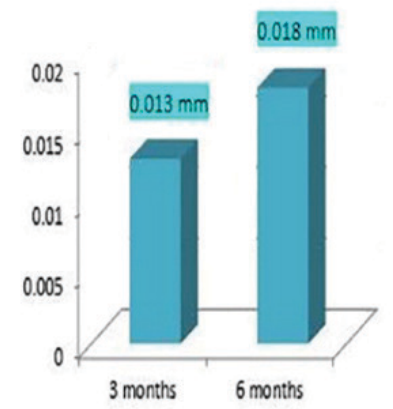

MEAN WEAR OF POLISHED ZIRCONIA CROWNS AFTER 3 AND 6 MONTHS

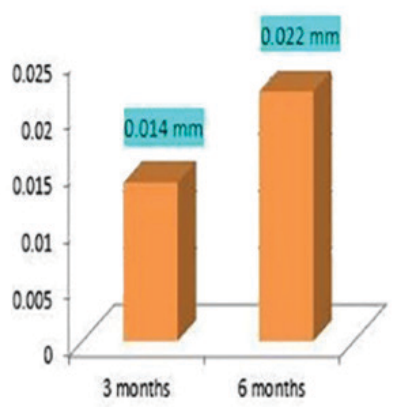

MEAN WEAR OF GLAZED ZIRCONIA CROWNS AFTER 3 AND 6 MONTHS
Figure 9: The difference in the mean wear of polished and glazed monolithic zirconia crowns at 3 months' and 6 months' time interval. 